\title{
Enhancement of overall equipment effectiveness (OEE) data by using simulation as decision making tools for line balancing
}

\author{
M.S. Abd Rahman', E. Mohamad', A.A. Abdul Rahman ${ }^{3}$
}

${ }^{1}$ Faculty of Engineering Technology Mechanical and Manufacturing, Universiti Teknikal Malaysia Melaka, Malaysia

${ }^{2,3}$ Faculty of Manufacturing Engineering, Universiti Teknikal Malaysia Melaka, Malaysia

\begin{tabular}{l} 
Article Info \\
\hline Article history: \\
Received Sep 3, 2019 \\
Revised Nov 6, 2019 \\
Accepted Nov 20, 2019 \\
\hline
\end{tabular}

\section{Keywords:}

Data analytics

Industry 4.0

Lean manufacturing

Overall equipment effectiveness

(OEE)

Simulation

\begin{abstract}
Nowadays, the digitalization of the production-based industries is driven by emerging technologies tools. The concept of lean manufacturing (LM) towards Industry 4.0 was developed where data analytics of engineering processes are analyzed and connected to reduce wastes. Many authors discuss about the benefits of extending data analytics as a method to support decision. However, the absence of comprehensive framework on how to embed LM and IT tools has existed as a new challenge. The aim of the research is to initiate a framework of model driven decision support system (MD-DSS) where data simulation and communication technologies are accompanied for manufacturing process improvement. In this research, Overall Equipment Effectiveness (OEE) data was captured through internet networking system and simulate to predict the improvement output. The main information flow route within MD-DSS are demonstrated in detail to show how decisionmaking process. To illustrate the applicability of the MD-DSS, it has been applied at food industry in Malaysia. The results show that the MD-DSS can easily be adopted in factories facilited with internet network to support decision-making of improvement plan activities.
\end{abstract}

Copyright $\odot 2020$ Institute of Advanced Engineering and Science. All rights reserved.

\section{Corresponding Author:}

Mohd Soufhwee bin Abd Rahman,

Faculty of Engineering Technology Mechanical and Manufacturing,

Universiti Teknikal Malaysia Melaka,

Hang Tuah Jaya, 76100 Durian Tunggal, Melaka.

Email: soufhwee@utem.edu.my

\section{INTRODUCTION}

Information such as data of engineering processes in current business allows manufacturing sectors to achieve real competitive advantage in marketplace. The definition of big data focuses not only on the size of data in storage but also on other important attributes of big data such as variety and speed [1-2]. Big data analytics will improve manufacturing efficiency by improving equipment service, reducing energy costs, and improving production quality [3]. Through data collecting from different sources such as equipment and customer management systems, manager can analyse and speed up decision making.

In LM, there are various type of data come from lean manufacturing tools (LMT) such as OEE, single minute Exchange of Dies (SMED), Kaizen, 5S, Value Stream Mapping (VSM), Jidoka, Kanban, Poka Yoke, Line Balancing and other [4-5]. Actually, data analytics in lean manufacturing tools such as the numbers of machines used, operators, operations time, volume of materials etc., will affect the success rate of a lean manufacturing implementation. However, data in LM generally are used for tracking purpose. The data is not extending to improve existing operations. Therefore, manufacturers need to acquire, store, analyze and use big data in order to take decisions related to the achievement of their supply chain and strategy goals [6]. 
One of the most challenging aspect in LM is to utilize the data analytics for process improvement. If problems happen, normally alternatives strategies are planned to solve the problem. However, characteristics of the decision should be determined before the decision makers make the judgement. A good judgement is one of the business strategies used to solve the problem in manufacturing industries. In the subject literature, the quality of decision-making processes is strengthened by the fact that they are based on the rule of Quality, Environment, Cost and Delivery (QECD). For example, the speed in deciding results should concern on the quality of product. The results must still be evolving market environment, customer expectations and demand for customization of product and faster delivery. Understanding cost vs benefits in flexibility and complexity of manufacturing situation is needed to clarify correctly.

For machine performance, manufacturer normally adopt LM through Total Productive Maintenance (TPM) as a systematic approach to machines, equipment and processes towards the integrity of production and quality performance. TPM focus on increase machine utilization, increase the capability of the machine equipment usage and minimize any breakdowns, small stops or slow running and defects in manufacturing processes. OEE is developed as part of the powerful and holistic improvement process known as TPM. TPM involves everyone in the organization in focusing on eliminating the six major losses through the measurement and monitoring of overall performance by using the parameter known as OEE [7].

Over the past decade, most research in OEE has emphasized the significant of OEE in industry. The roles of OEE have been studied extensively which expressed that OEE is one of the performance measurement tools that used to measure various type of production losses and identify area of process improvement [8]. OEE is a preeminent practice for monitoring and enhancing efficiency of the manufacturing processes, for example, machines. It takes the most common sources of manufacturing productivity losses and places them into three main categories which are Availability, Performance and Quality [9]. Meanwhile, OEE is used to calculate for machine efficiency only. In this research, OEE will be used to calculate for mixing, rolling, extrusion and fried, and cooling machine only. The aim of the research is to initiate a framework of MD-DSS where data simulation and communication technologies are accompanied for manufacturing process improvement.

\section{LITERATURE REVIEW}

The OEE is the key metric of TPM which described OEE is the best practice to monitor and enhance the real execution of a relative tool to its performance capabilities under ideal manufacturing conditions [10]. OEE focus on the whole manufacturing environment, the equipment availability, as well as, the production efficiency while the equipment is available to run product, also, the efficiency loss that results from scrap, rework, and yield losses [11].

Three factors are needed to consider the OEE value as show below formula:

$$
\mathrm{OEE}=\text { Availability } \mathrm{x} \text { Performance rate } \mathrm{x} \text { Quality rate }
$$

Availability: Availability takes into account downtime loss which includes any events that stop production process for an appreciable length of time. Downtime can be characterized into planned downtime and unplanned downtime. Planned downtime is excess capacity, planned breaks, planned maintenance, communication breaks and meeting. Whereas unplanned downtime refers to breakdowns, set-up and adjustment, late material delivers and operator availability. Availability is ratio of required availability minus the downtime to required availability [12].

$$
\text { Availability }=\frac{\text { Required availability }- \text { downtime }}{\text { Required availability }}
$$

Performance: Performance rate in OEE metric is to measure the speed at which the work centre runs as a percentage of its designed speed. It is a comparison of the actual output with what the machine ought to produce in a similar time. Performance rate takes into account speed losses. It can be improved by eliminating equipment idling and minor stoppage and reduced speed losses. Hence, performance rate can be characterized as net operating time per operating time [13].

$$
\text { Performance rate }=\frac{\text { Net operating time }}{\text { Operating time }}
$$

Quality: Quality rate is one of the elements in OEE metric that represents the good units produced as a percentage of the total units produced. Quality rate takes into account qualitative losses. It refers to the first 
pass yield. It can be enhanced by eliminating quality defect and rework losses and start-up losses. Therefore, quality rate can be expressed as the processed quantity minus the volume or number of defective quantities, then divided by the processed quantity.

$$
\text { Quality rate }=\frac{\text { Processed quantity }- \text { defective quantity }}{\text { Processed quantity }}
$$

\section{METHODOLOGY}

Smart productions are facilitated by integrating the physical and virtual worlds [14]. In the first stage, internet networking concept, sensors are used to capture the data. Data is installing into the database at the machine before transmitting to server through intranet. Through MySQL command, these data are compiled and coding to align the simulation requirement inputs. This is the main basic of networking system towards Industry 4.0. With the help of the concept, all physical devices can be connected to the Internet. A framework of MD-DSS is to provide a more meaningful and effective framework on how LMT data can be simulated for decision making. The proposed framework is illustrated as Figure 1.

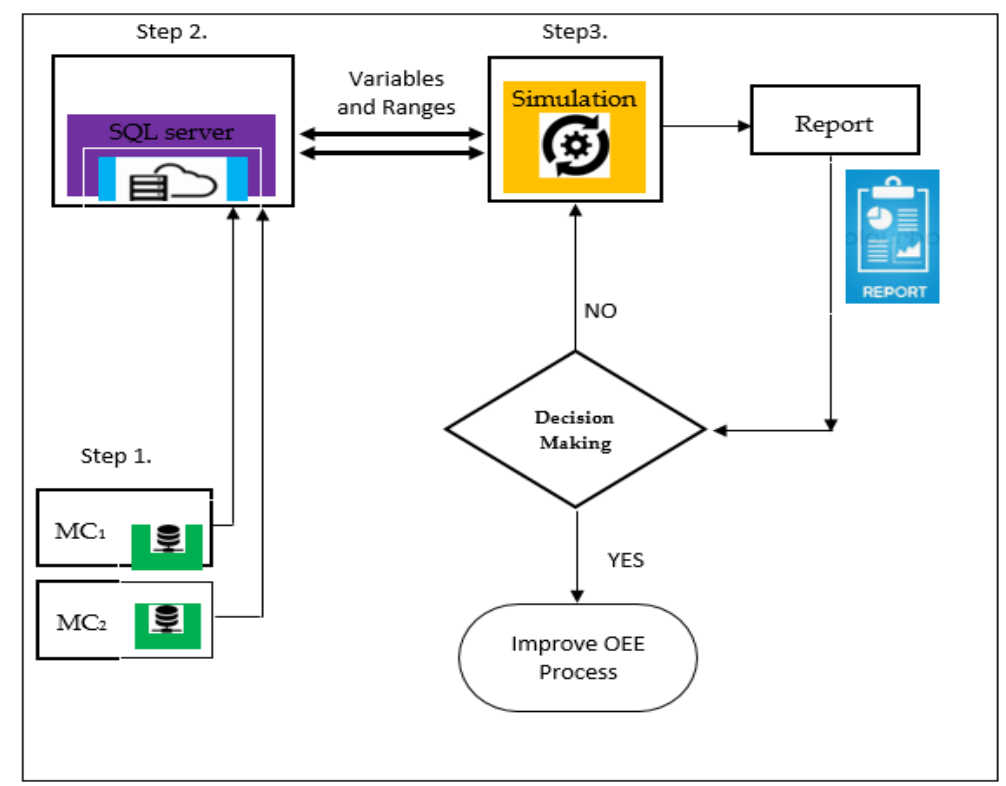

Figure 1. Model-Driven Decision Support System (MD-DSS) framework

\section{Step 1: Collecting Data:}

Data for this study were collected using a web-based program, where PHP language, web-based database MySQL, and web serve provider Linux are connected. The PHP + MySQL platform is a famous database-driven web service that facilitates the proposed framework. The sensors at the machines are functioned to collect data processes. A set of data retrieved by sensors before transmitted to database MySQL [14]. Through intranet and SQL command, all required data from selected machines are compiled into database MySQL [15].

Step 2: Storing Data:

Compiled data at database MySQL were aligned based on the simulation input such as cycle time, quantity, number of operators etc. A simulation is used to simulate the production system to figure out the real operation of the manufacturing system in the production line.

Step 3: Simulation and Decision Makers

Simulation is a tool to assist in the decision to implement LM principles at an existing assembly operation [16-17]. Models are developed similar with the existing production system. In addition to the manufacturing processes, the related elements such us warehousing, inventory quantity, transportation method, and production quality control system (QMS) are included in the model to enable the quantification of lean manufacturing's impact on the total system. Simulation experiments measure each system's resource 
requirements and performance, thereby quantifying benefits to be derived from applying the shop-floor principles of lean manufacturing [18]. In this research, to demonstrate the MD-DSS, discrete event simulation (DES) will be applied as a tool to support organizations with the decision to implement lean manufacturing by counting the benefit based on the specific situation [19]. Before decision making has made, DES model created to estimate the system capability for the optimal settings of decision variables. The decision makers define the decision variables or scenarios which can be changed based on their allowable ranges.

Decision making will be made based on the organizations rules. Based on that, normally management will specify how to operate the action in certain conditions. Therefore, it is important align operational and strategic decision making with the organizations rules. And the organizations should have culture of decisionmaking based on evidence for continuous improvement. Lack of awareness about organization direction will give impact to the output results.

\section{IMPLEMENTATION EXAMPLES}

\subsection{Problem Statement}

The research was done at the production line where several of the machines were not performed ideally due to machines breakdown and speed lost. In the same time, the bottleneck issue at production line is difficult to determine accurately without OEE activities. Then, through OEE values generated via simulation can help engineers to determine the root cause of the bottleneck.

\subsection{Manufacturing Process}

There are 6 main processes in the production line such as preparation, mixing, rolling, fried extrusion, cooling and packaging as illustrate in Figure 2. In the preparation station, the raw ingredients used for clay pot noodles are prepared. Those ingredients such as flours and water are then mix together to form dough in a mixing machine. Next, the dough is then undergo rolling process to flatten it out by using roller machine. The rolled out thin sheet is then undergo extrusion and fried process in an extruder. The step is followed by cooling to cool down the hot fried noodles. Next, the noodles are undergo inspection and packaging by operators. Operator will check quality, if the noodles are out of specification, the noodles will be rejected. However, the qualified noodles will undergo packaging process by operators. After running all the process, all the clay pot noodles are ready to send to warehouse and ready for shipping.

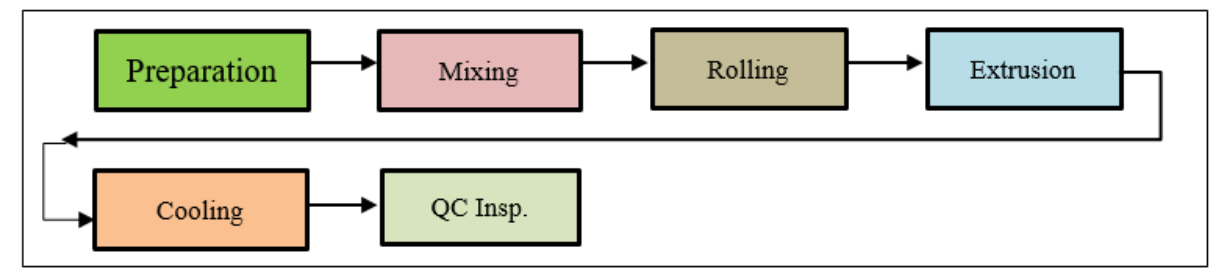

Figure 2. Pictorial diagram of clay pot noodles manufacturing process

\section{RESULTS AND DISCUSSION}

OEE considers all losses include downtime loss, speed loss and quality loss, which bring about a measure of truly productive manufacturing time [20-21]. The purpose of used these data is to make a decision making based on simulation results. OEE of each machine can be computed based on the product of availability, performance and quality [22].

From the data set compiled by the server, a calculation of cycle time of each machines were determined. Cycle time of each machine as in Table 1 are required to create a simulation model based on the existing design lay out at production line. The value of OEE was calculated through the below formula:

$$
\begin{aligned}
& \text { Normal time }=\text { Net run time }(1+\text { OEE rating }) \\
& \text { Standard time }=\text { Normal time } \mathrm{x}(1+\text { allowance factor })
\end{aligned}
$$

OEE refer to the overall machine effectiveness in which how efficient the machine can perform. Net run time refer to the time where the machine is running at ideal speed without any downtime and speed loss to manufacture the total quantity of products. Hence, normal time is the product of net run time and OEE rating. 


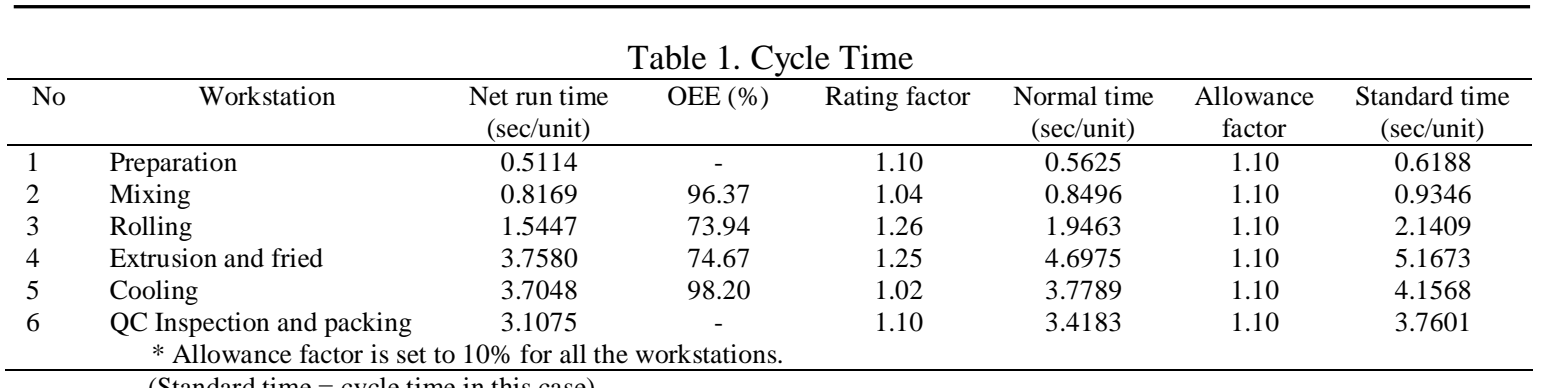

(Standard time $=$ cycle time in this case)

\subsection{Verification of the Simulation Model}

Arena simulation modelling as Figure 3, needs to be verified before completing the whole simulation project. The objectives of the verification model are to ensure the entities enter the system according to sequence. Verification start with identify the number of workstations in the clay pot noodles production line. There are six workstations in clay pot noodles production line, that are preparation, mixing, rolling, extrusion and fried, cooling and quality control (QC) inspection and packaging. The simulation is test run for 3.05 hours for one batch production which are $90 \%$ same with the actual production line.

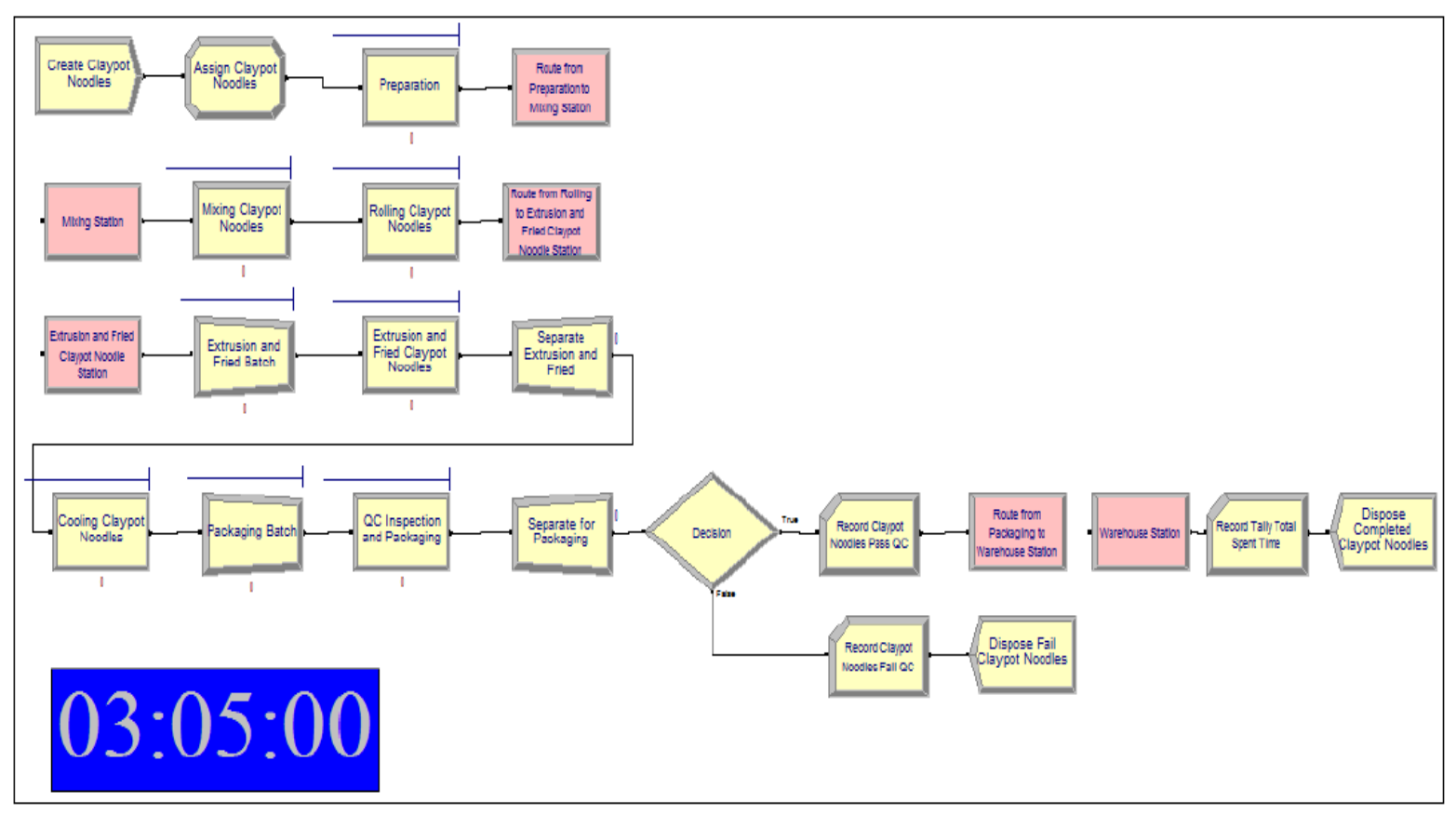

Figure 3. Simulation arena logic model

Validation of model is carried out by correlation result between the actual production with the simulation result as shows in Table 2. The simulation is set to run for one batch that is 3.05 hours. The accuracy of actual output per batch in July 2019 and simulation output is compared. Based on the result, the accuracy of output is above $95 \%$ which is just a slightly bias between the actual production output and the simulation output. This can be seen clearly into work in progress (WIP), there are 5 units of clay pot noodles still undergo processing after 3.05 hours at the cooling workstation. Although there is some bias in actual simulation result, but the simulation result is still in acceptable range. Thus, the simulation is validated.

Table 2. Comparison between Actual Output and Simulation Output

\begin{tabular}{cccc}
\hline Clay pot Noodles & Actual output (units) & Simulation output (units) & Accuracy (\%) \\
\hline One batch & 600 & 595 & 99.17 \\
Counter pass & 565 & 560 & 99.12 \\
Counter fail & 35 & 35 & 100 \\
\hline
\end{tabular}


The research show that benchmark given by Nakajima (2004) as World-Class OEE levels of $85 \%$ [23]. Based on the result, the OEE of all the four machines in the clay pot noodles production line showed above $70 \%$ due to all the four machines is still in new condition that bought one year ago. In this study, machine that out of the World-Class level are rolling and extrusion and fried machine. Internal improvement target should be focus on these two machines which depends on the machine criticality in the manufacturing system, in order to minimize the six major losses.

Bottleneck is refer to the longest queue from the entire of manufacturing process. Almost every system has a bottleneck, even if it is a minor one, if every system was running at full capacity, at least one machine would be accumulating processes. Bottleneck of the process can be determined through queue in the simulation process. Queue arise when the arrival time is faster than the processing time. In this simulation, incoming entity are queue or wait before processed. Based on the graph of average waiting time for each workstation, it can be clearly seen that extrusion and fried workstation experienced the highest average waiting time due to 6 units of claypot noodles need to enter in sequence to each of the stainless steel filter mesh just proceed for frying process. Hence, the bottleneck for extrusion and fried workstation is the highest among all the workstations, that is 45.75 s per unit as shows in Figure 4.

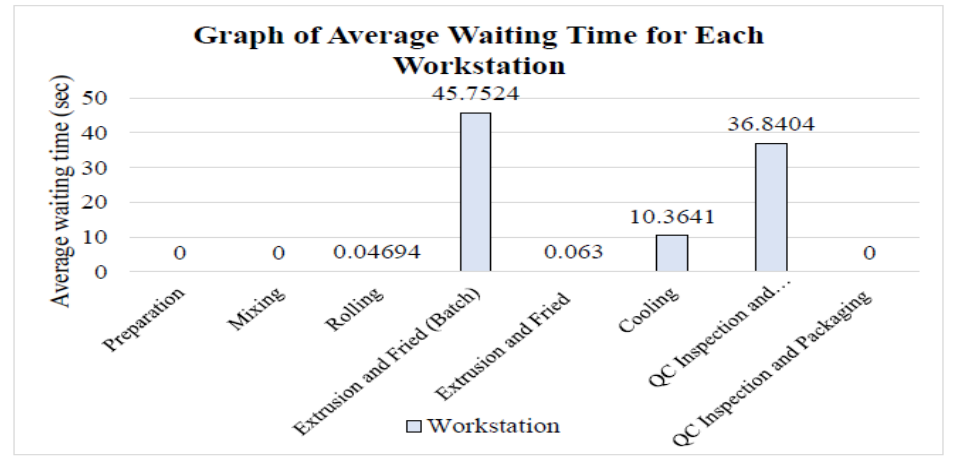

Figure 4. Average waiting time for every workstation

\section{CONCLUSION}

Throughout this research, simulation can also be used as a to measure production performance or usage under different operating environment using different types of variables. From the results, management is enabled to decide the accurate decision based on the actual real data from existing production line. This article has described the development of a next generation production system with a focus on how to combine simulation and lean tools such as OEE in decision making. Concluding, this paper shows an approach which enables manufacturer to fully understand the chances and potential in the framework of MD-DSS to develop long term strategies to fit new business challenges. The resulting method of framework can be defined as a very effective supervision tool which enables decision makers to reach their predefined targets during the process of implementation of LM.

\section{ACKNOWLEDGEMENTS}

Authors would like to say thank you very much where the research was supported by Universiti Teknikal Malaysia Melaka (UTeM) under the Applied Oriented Research Grant (AORG) / registered number: PJP/2017/FTK-AMC/S01563.

\section{REFERENCES}

[1] A. McAfee, et al., "Big data: The management revolution," Harvard Business Review," vol/issue: 90 (10), pp. 6068, 2012.

[2] B. Di Martino, et al. "Big data (lost) in the cloud," International Journal of Big Data Intelligence, vol/issue: 1(1-2), pp. 3-17, 2014.

[3] A. Santana, et al., "Costing models for capacity optimization in Industry 4.0: Trade-off between used capacity and operational efficiency," Procedia Manufacturing, vol. 13, pp. 1183-1190, 2017.

[4] R. Sundar et al., "A review on lean manufacturing implementation techniques," Procedia Engineering, vol. 97, pp.1875-1885, 2014.

[5] T. Wagner et al., "Industry 4.0 impacts on lean production systems," Procedia CIRP, vol. 63, pp. 125-131, 2017.

Enhancement of overall equipment effectiveness (OEE) databy using simulation as... (M.S. Abd Rahman) 
[6] B. Di Martino, et al., "Big data (lost) in the cloud," International Journal of Big Data Intelligence, vol/issue: 1(1-2), pp. 3-17, 2014.

[7] R. Dubey, et al., "The impact of big data on world-class sustainable manufacturing," The International Journal of Advanced Manufacturing Technology, vol/issue: 84(1-4), pp. 631-645, 2016.

[8] P. M. Gibbons, and S. C. Burgess, "Introducing OEE as a measure of lean Six Sigma capability," International Journal of Lean Six Sigma, vol/issue: 1(2), pp. 134-156, 2010.

[9] P. Muchiri and L. Pintelon, "Performance measurement using overall equipment effectiveness (OEE): literature review and practical application discussion," International Journal of Production Research, vol/issue: 46(13), pp. 3517-3535, 2008.

[10] I. H. Afefy, "Implementation of total productive maintenance and overall equipment effectiveness evaluation," International Journal of Mechanical \& Mechatronics Engineering, vol/issue: 13(5), pp. 69-75, 2013.

[11] C. J. Bamber, et al., "Cross-functional team working for overall equipment effectiveness (OEE)," Journal of Quality in Maintenance Engineering, vol/issue: 9(3), pp. 223-238, 2003.

[12] T. Pomorski,"Managing overall equipment effectiveness [OEE] to optimize factory performance," 1997 IEEE International Symposium on Semiconductor Manufacturing Conference Proceedings (Cat. No.97CH36023),

[13] pp. 33-36, 1997.

[14] S. R. Vijayakumar and S. Gajendran, "Improvement of overall equipment effectiveness (OEE) in injection moulding process industry," IOSR J Mech Civil Eng, vol/issue: 2(10), pp. 47-60, 2014.

[15] P. Godfrey, "Overall equipment effectiveness," Manufacturing Engineer, vol. 81, no. 3, pp. 109-112, 2002.

[16] E. Westkämper, 2007. Digital Manufacturing in the global Era. In Digital Enterprise Technology (pp. 3-14). Springer, Boston, MA.

[17] F. F. Chen, "Decision support for lean practitioners: A web-based adaptive assessment approach," Computers in Industry, vol/issue: 60(4), pp. 277-283, 2009.

[18] R. Singh et al., "Overall Equipment Effectiveness (OEE) calculation-Automation through hardware \& software development," Procedia Engineering, vol. 51, pp. 579-584, 2013.

[19] E. Mohamad, el al., "Improved decision making in lean manufacturing using simulation-based approach. International Journal of Agile Systems and Management," vol/issue: 10(1), pp. 34-48, 2017.

[20] E. Mohamad, et al., "A Simulation-Based Approach for Lean Manufacturing Tools Implementation: A Review," J. Eng. and Appl. Sc, vol/issue: 11(5), pp. 3400-3405, 2016.

[21] B. J. Schroer, "Simulation as a tool in understanding the concepts of lean manufacturing," Simulation, vol/issue: 80(3), pp. 171-175, 2004.

[22] S. Salama, and A.B. Eltawil, "A decision support system architecture based on simulation optimization for cyberphysical systems," Procedia Manufacturing, vol. 26, pp. 1147-1158, 2018.

[23] P. Godfrey, "Overall equipment effectiveness," Manufacturing Engineer, vol/issue: 8(3), pp.109-112, 2002.

[24] S. Loughlin, "A holistic approach to overall equipment effectiveness (OEE)," Computing \& Control Engineering Journal, vol/issue: 14(6), pp. 37-42, 2004.

[25] R. Domingo, and S. Aguado, "Overall environmental equipment effectiveness as a metric of a lean and green manufacturing system. Sustainability,” vol/issue: 7(7), pp. 9031-9047, 2015.

[26] A. K. Gupta, and R.K. Garg, "OEE improvement by TPM implementation: A case study," International Journal of IT, Engineering and Applied Sciences Research, vol/issue: 1(1), pp. 115-124, 2012.

\section{BIOGRAPHIES OF AUTHORS}

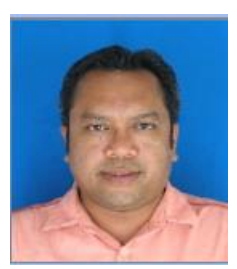

Ts. Mohd Soufhwee Abd Rahman received his Bachelor of Mechanical Engineering (Industrial) in 1999 from the Universiti Teknologi Malaysia (UTM). He has 10 years' experiences in manufacturing industries before joined the university as academia in 2009. He obtained his Master of Science in 2013 and now he is one of the lecturers in Faculty of Engineering Technology Mechanical and Manufacturing. His research interest is in lean manufacturing, quality engineering and management system related to Industry 4.0.

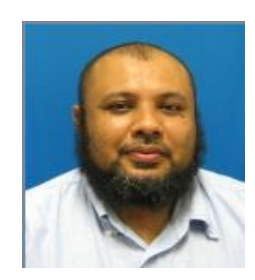

Effendi Mohamad has been serving Faculty of Manufacturing Engineering in Universiti Teknikal Malaysia Melaka as a lecturer since 2005. Prior to his involvement as an academician, he worked in NEC Semiconductors Sdn Bhd, Perodua Sales Sdn Bhd and ST Microelectronics Sdn Bhd in various engineering capacities such as industrial engineer and process engineer. He received his Bachelor's degree in Manufacturing Engineering from University Malaya Kuala Lumpur and Master's degree in Manufacturing Management from Coventry University United Kingdom. He completed his Doctoral course in Intelligent Structures and Mechanics Systems Engineering in University of Tokushima, Japan. He has also served as a visiting professor/scholar at various institutes including, Tokushima University, Japan and University Brawijaya, Indonesia. Currently, he is Associate Profesor in Faculty of Manufacturing Engineering, Universiti Teknikal Malaysia Melaka and is actively involved in consultation and research work with various manufacturing organizations. 


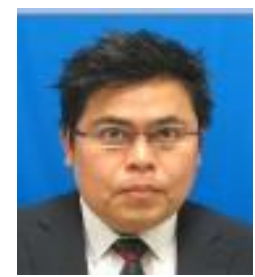

Ir. Dr.-Ing. Azrul Azwan Rahman received his Bachelor of Engineering (with honours) in Mechanical Engineering from the Universiti Kebangsaan Malaysia, in 2002, Master of Science in Global Production Engineering from the Technische Universität Berlin, Germany, in 2005, and Doctor of Engineering in Assembly Technology and Factory Management from the Technische Universität Berlin, Germany in 2013. He joined Malaysia Shipyard and Engineering Sdn. Bhd., Johor, Malaysia, in 2002. Since 2003, he has been with the Faculty of Manufacturing Engineering at the Universiti Teknikal Malaysia Melaka (UTeM), where he is currently the head of Smart Manufacturing and Automation Cluster at the Advanced Manufacturing Centre (AMC). His research interests lie in the area of integrated manufacturing systems, ranging from the theory of design to implementation, cyber physical system, manufacturing automation and simulation of manufacturing system. 